\title{
Event models and the fan effect
}

\author{
G. A. $\operatorname{Radvansky}^{1} \cdot{\text { Andrea E. O' } \text { Rear }^{1} \text { - Jerry S. Fisher }}^{1}$
}

Published online: 17 May 2017

(C) Psychonomic Society, Inc. 2017

\begin{abstract}
The current study explored the persistence of event model organizations and how this influences the experience of interference during retrieval. People in this study memorized lists of sentences about objects in locations, such as "The potted palm is in the hotel." Previous work has shown that such information can either be stored in separate event models, thereby producing retrieval interference, or integrated into common event models, thereby eliminating retrieval interference. Unlike prior studies, the current work explored the impact of forgetting up to 2 weeks later on this pattern of performance. We explored three possible outcomes across the various retention intervals. First, consistent with research showing that longer delays reduce proactive and retroactive interference, any retrieval interference effects of competing event models could be reduced over time. Second, the binding of information into events models may weaken over time, causing interference effects to emerge when they had previously been absent. Third, and finally, the organization of information into event models could remain stable over long periods of time. The results reported here are most consistent with the last outcome. While there were some minor variations across the various retention intervals, the basic pattern of event model organization remained preserved over the two-week retention period.
\end{abstract}

Keywords Event cognition · Event models · Mental models · Fan effect $\cdot$ Forgetting

G. A. Radvansky

gradvans@nd.edu

1 Department of Psychology, University of Notre Dame, 218C Haggar Hall, Notre Dame 46556, IN, USA

\section{Introduction}

As demonstrated by Ebbinghaus (1885), the retention of knowledge is reduced with the passage of time as there is increased forgetting. This retention curve (often called a forgetting curve) generally follows a power function (e.g., Wixted \& Ebbesen, 1991) when averaged across items. However, there is reason to suspect that the forgetting of individual memories follows an exponential function (Anderson, 2001; Anderson \& Tweney, 1997; Averell \& Heathcote, 2011; Murre \& Chessa, 2011), with a power function arising from averaging across many exponential functions. Regardless of the actual form of the retention curve, the primary issue for most studies is the loss of information over time. In comparison, the aim of the current study is to explore how changes in retention influence the organization of information into event models.

\section{The retention of event models}

The ubiquity of the retention function is one of the basic tenants of human memory. However, the rate of forgetting varies under different circumstances. Importantly, in the current study, is how forgetting is influenced by the level of representation. In a study by Kintsch, Welsch, Schmalhofer, and Zimny (1990; see also, Radvansky, Zwaan, Curiel, \& Copeland, 2001) people read narrative texts, and memory was tested at various time intervals, up to a week later. This study used a procedure, developed by Schmalhofer and Glavanov (1986), that separates retention levels for surface form, textbase, and event model knowledge (van Dijk \& Kintsch, 1983). The surface form corresponds to the actual words and syntax used (i.e., verbatim memory). The textbase corresponds to a representation of the propositional idea units 
that were conveyed by the text apart from the wording, such as treating paraphrases as being similar to the original statements.

Finally, the event model (sometimes also called a mental model or situation model) corresponds to a referential representation not of the text itself, but of the circumstances it describes (Johnson-Laird, 1983; Radvansky, 2012; Radvansky \& Zacks, 2011; 2014; Zwaan \& Radvansky, 1998). Here, inferences derived from a text would not be distinguished from ideas that were actually presented. Schmalhofer and Glavanov's (1986) method, used by Kintsch et al. (1990), separates out the influences of these three levels and has been used extensively (Bohay, Blakely, Tamplin, \& Radvansky, 2011; Fletcher \& Chrysler, 1990; Narvaez, Radvansky, Lynchard, \& Copeland, 2011; Radvansky \& Copeland, 2004; Radvansky, Copeland, \& von Hippel, 2010; Radvansky, Copeland, \& Zwaan, 2003; Radvansky et al., 2001; Radvansky, Gibson, \& McNerney, 2014; Zwaan, 1994).

Kintsch et al. (1990) had people read texts and then tested memory at these three levels at four retention intervals (up to 4 days later). An important finding was the shape of the three retention curves. The retention curve for the surface form showed a rapid decline, quickly reaching chance levels. In comparison, for the textbase level forgetting was less dramatic, although there was clearly a decline. Importantly, event model memory showed little to no decline.

\section{Differential fan effect}

Based on Kintsch et al.'s (1990) result, there appears to be little in the way of forgetting at the event model level after several days of retention. The aim of the present study is to further explore this. However, rather than assessing retention over time at various levels of processing, we assessed whether there are any changes in the integration and separation of information into event models. To do this, we draw on prior research that has used the differential fan effect (e.g., Radvansky \& Zacks, 1991). This paradigm allows us to assess whether information has been stored in separate event models, thereby producing interference at retrieval, or integrated into a common event model, thereby avoiding retrieval interference.

For a differential fan effect paradigm, people memorize a list of sentences. For the sake of exposition, assume that six of the sentences memorized correspond to Sentences 1-6 below.

1. The potted palm is in the hotel.

2. The potted palm is in the museum.

3. The potted palm is in the barber shop.

4. The welcome mat is in the laundromat.

5. The pay phone is in the laundromat.

6. The oak counter is in the laundromat.
What is critical here is that in both Sentences 1-3 and Sentences 4-6, there is a single concept (either potted palm or laundromat) that has three associations with it. For Sentences 1-3, there is a single object in three locations. As such, this conforms to the Multiple Locations condition. Because these three sentences are likely to be interpreted as separate events, a separate event model is likely to be created for each sentence. In comparison, for Sentences 4-6, there are multiple objects in a single location. As such, this conforms to the Single Location condition. Because these three sentences are likely to be interpreted as referring to multiple objects in one place at the same time, this information is likely to be integrated into a single event model.

After memorization to a specified criterion, a recognition test is given in which people are presented with individual sentences, and studied/nonstudied responses are made, with response time being the measure of primary interest. The typical finding is that in the Multiple Locations condition there is a fan effect, with an increase in response time with an increase in the number of associations. That is, the more places that an object is in, there are more event models that contain the object in the memory probe (potted palm in our example). These event models compete with one another, thereby slowing response time and producing the fan effect.

In comparison, typically there is no fan effect in the Single Location condition. Instead, the response times are relatively flat. That is, the number of objects in a location is less important because they can be integrated into a single event model. Because there are no competing event models for that location, there is no interference at retrieval, and no fan effect is observed. Thus, the differential fan effect is a pattern of data in which there is a clear fan effect in one condition, such as the Multiple Locations condition, but not in another condition, such as the Single Location condition (Radvansky \& Zacks, 1991).

The differential fan effect is a robust finding (Radvansky, 1998, 1999, 2005, 2009; Radvansky \& Zacks, 1991). It does not depend on the ordering of the concepts in the sentence, nor whether definite or indefinite articles are used (Radvansky, Spieler, \& Zacks, 1993). It occurs with both sentences and pictures (Radvansky \& Copeland, 2006b). It is not dependent on spatial materials. It is observed with materials that describe temporal (Radvansky, Zwaan, Federico, \& Franklin, 1998) and ownership relations (Radvansky, Wyer, Curiel, \& Lutz, 1997). Even with spatial materials, people do not necessarily organize event models around spatial locations. When study sentences describe people in small locations that typically are occupied by a single person at a time (e.g., a witness stand), participants organize their event models around the person concepts (Radvansky et al., 1993).

The differential fan effect suggests that people interpret the study sentences referentially in terms of the described situations using event models (Radvansky, 2005). Finally, while this pattern is observed in both younger and older adults 
(Radvansky, Zacks, \& Hasher, 2005), the integration of information into event models may be influenced by working memory span, although the management of retrieval interference is not (Radvansky \& Copeland, 2006a). ${ }^{1}$

Given that it is well established how the organization of information into event models influences this pattern of data and that it has been frequently replicated, we can leverage this paradigm to address how changes in memory over long periods of time influence this organization. In the current study, people first memorized sentences about objects in locations. Then, people were given a recognition test either immediately after learning (as has been done in previous work), $1 \mathrm{~h}, 1$ day, 1 week, or 2 weeks later. These five retention intervals allow us to assess changes in the pattern of data over time.

The assessment of the associative retrieval interference that is found with the fan effect has been measured for retention intervals beyond immediate testing in only a handful of studies. Singer and Jakobson (1991) tested memory after $24 \mathrm{~h}$ and found evidence of a fan effect, although they did not test immediately after learning, nor at any other retention intervals. Reder and Wible (1984) assessed the fan effect immediately and 2 days later. What they found was that the fan effect decreased over the retention interval, indicating less interference over time. This study used study facts about people, in which each person was engaged in one or two specific thematic activities (e.g., playing tennis). During learning, all of the study facts about a given person were presented together along with a title that highlighted these. Thus, the materials were more mini-stories than the collection of facts typically found in fan effect studies. During the testing, participants were asked to make either recognition or plausibility judgments. Our concern is only with the recognition judgments. Most centrally, they found a smaller fan effect over a longer delay. However, it should be noted that nonstudied probes were thematically inconsistent with the studied items. Thus, the decrease in the fan effect over time was attributed to an increase in using plausibility rather than recognition judgments (Reder \& Anderson, 1980). This is avoided in the current study.

\footnotetext{
${ }^{1}$ While we interpret the differential fan effect from an event model perspective, there is another view. In a single paper reporting a single experiment, Sohn, Anderson, Reder, and Goode (2004) argue that the differential fan effect is due to a differential focus on either of the two primary concepts in the study sentences. We disagree with this interpretation for a number of reasons, several of which are noted by Radvansky and Copeland (2006). For our differential fan effect studies, an important finding is a significant Condition $\times$ Fan interaction. The corresponding interaction for Sohn et al.'s study would be a significant Focus Fan $\times$ Nonfocus fan interaction. This interaction was not significant for the response time data, which is the primary dependent measure in differential fan effect studies. This interaction was significant for their error rate data, $F(2,68)=4.99, M S E=.01, p<.01, \eta_{p}{ }^{2}=.12$. So, the critical interaction is only partially there. For our study, this interaction is larger and present, both for the response times, $F(2,390)=39.58, M S E=94,364, p<$ $.001, \eta_{p}{ }^{2}=.17$, and for the error rates, $F(2,390)=8.22, M S E=.005, p<.001$, $\eta_{p}{ }^{2}=.04$.
}

A third study that has assessed the fan effect beyond a single experimental session was done by Peterson and Potts (1982). In one of their two experiments, they assessed the fan effect immediately and after a 2 -week retention interval. They also found that the fan effect decreased over time. In their study, the study sentences were facts about well-known people (e.g., Jesse James). They were less about specific events in the world (more episodic information) and more about additional knowledge for people to incorporate into their wellestablished memories (more semantic information). They also found that the size of the fan effect decreased with longer delays. However, the nature of these materials may also have led participants to adopt a plausibility strategy during recognition (cf. Reder \& Anderson, 1980) rather than memory retrieval. Moreover, as Peterson and Potts themselves repeatedly noted, especially for the 2-week retention interval, there was a speed-accuracy trade-off, thereby compromising any interpretation of their results. Finally, they did not assess a differential fan effect, which is of primary concern to our study.

Thus, overall, while there have been a few studies assessing the fan effect over longer retention intervals, it is not possible to clearly assess the impact of these retention intervals on the retrieval processes of concern here. Moreover, there has been no assessment of the differential fan effect, which is of critical interest for this study.

\section{Long-term memory consolidation and interference}

Over time, memories may go through a process of consolidation in which they are made more permanent in memory. Consolidation is a neurological process that results in a changing of the neural connections in the brain (e.g., Meeter \& Murre, 2004; Wixted \& Cai, 2013). What is of particular importance here is what influence the passage of time, and the consolidation of memories, has on patterns of retrieval interference. In this section we outline three possible outcomes in terms of the pattern of associative interference at retrieval and the passage of time. These possibilities are that the passage of time will result in less interference, more interference, or no change in the pattern of performance. For some of these possibilities, there are studies that suggest that memory consolidation can change the nature of the memory representations in some way to the point of changing a later experience of retrieval interference. These studies will be discussed next, followed by our exploration of the three possible outcomes.

While we are unaware of any studies directly assessing the effects of consolidation on interference per se, there are some studies assessing the influence of sleep on interference. What has been found is that when people memorize lists of paired associates using A-B A-C paradigms, with both associations being learned prior to the retention interval, the retroactive interference that is initially observed is reduced or eliminated 
following sleep compared to a comparable waking period (Abel \& Bäuml, 2014; Drosopoulos, Schulze, Fischer, \& Born, 2007; Ekstrand, 1967). It has also been found that proactive interference effects can be reduced with sleep (Abel \& Bäuml, 2014), although this is not always found (Drosopoulos et al., 2007; Ekstrand, 1967). Note that in these studies, the sleep/wake periods occurred after the A-B and A-C lists had both been presented. Thus, the assessment is whether the previously observed retroactive or proactive interference remains after a sleep or wake period. This reduction in interference may occur because the memories for the different paired associate lists are more strongly separated from one another, thereby producing less interference. Extrapolating these findings, it seems reasonable to think that retrieval interference effects can be reduced by longer retention intervals given that retention across multiple days would involve multiple sleep periods, at least when those interference effects are a result of mutually exclusive associations that occur during different periods of time.

The current study explored the influence of long-term memory consolidation on later associative retrieval interference based on how information is integrated or segregated into event models. Note that there have been very few explorations of the influence of retention interval on the fan effect per se, and none on the differential fan effect. As a result, there is very little to base our predictions upon. One possible outcome is that, like the prior work on retroactive and proactive interference with sleep (Abel \& Bäuml, 2014; Drosopoulos et al., 2007; Ekstrand, 1967), it will be found that there will be (a) a reduction in the fan effect in the Multiple Locations condition because overlapping memory representations compete less with each other, and (b) no influence on the pattern of data in the Single Location condition because there is no interference in this condition to start with.

A second possibility is that, unlike the previous work on proactive and retroactive interference, there will be (a) an increased fan effect in the Multiple Locations condition, and/or (b) an emergent fan effect in the Single Location condition. In the prior work on retroactive and proactive interference with sleep, the different list items producing interference are separated into different time periods. Because hippocampal processes are known to help segregate different information from different contexts (e.g., Manrique et al., 2009), the process of consolidation may help to further this, thereby reducing the observed proactive and retroactive interference effects. In comparison, in these fan effect experiments, the various items that are associated are intermixed within the same list. Thus, there is no separation in time and space within the context of the experiment. As such, because they continue to be part of the same experimental event, they may be further bound together on this dimension during consolidation, rather than segregated, causing interference effects to emerge over time. Moreover, it is also possible that the event model organization created at the time of learning may be fragile and start coming apart over time, also allowing for interference effects to become larger or emerge.

Finally, a third possibility, also unlike the previous work on retroactive and proactive interference effects, is that there may be no change in the pattern of data for either the Multiple Locations or Single Location conditions. After all, as noted earlier, Kintsch et al. (1990) and Radvansky et al. (2001) showed there is little to no forgetting at the event model level after up to a week later. However, this work did not touch on the organization of information at the event model level as the current study does. It only assesses overall accuracy levels. This absence of a change over time may occur, again, because retroactive and proactive interference effects are defined in terms of different paired associate lists that occur in different time frames. In comparison, the event models created of the described situations in these fan effect studies are not tied to different experimental events, but are part of the same extended experimental event. What defines the events in this case are the differences between the described events, and whether information is segregated or integrated into these for the Multiple Locations and Single Location conditions, respectively. As such, provided that the basic structure of these models does not degrade over time, this event model organization should still be evident even after consolidation has had an opportunity to occur. Therefore, the differential fan effect should be largely unchanged.

\section{Experiment}

The aim of the current study was to explore whether longer retention intervals would alter the basic pattern of event model organization as revealed by the differential fan effect. The three possibilities outlined earlier that are tested here are that (a) retrieval interference will dissipate, facilitating recognition in the Multiple Location condition, (b) retrieval interference will increase as the event models come apart, hindering recognition in the Single Location condition, and (c) the differential fan effect will remain largely unaffected over the various retention intervals.

\section{Method}

Participants. A total of 200 participants, 40 in each of the five groups, were recruited from the participant pool in the Department of Psychology at the University of Notre Dame. They each received partial course credit for their participation. This research was approved by the Institutional Review Board at the University of Notre Dame.

Materials The materials were generated in the same manner as previous studies (e.g., Radvansky et al., 1993). Essentially, 
people first memorized a list of 18 sentences of the form "The object is in the location." To make clear the structure of the study lists, the structure of the study list design, for a hypothetical participant, is shown in Fig. 1 in terms of the pattern of object-location associations, and in Fig. 2 in terms of the organization of the information into event models. Each participant had a unique study list that was generated through random pairings of objects and locations that resulted in one to three associations with each object and location concept (thus defining Fan Levels 1-3). The conditions of primary interest are those in which either a single object is associated with several locations (Multiple Locations condition) or a single location is associated with several objects (Single Location condition). To provide the needed number of associations for the critical sentences, as shown in Fig. 1, the study lists included 2-3, 3-2, and 3-3 fan items $(X-Y$ refers to $\times$ number of associations with the object and $Y$ number of associations with the location). To more appropriately analyze the data, so that the same data would not be used for Fan Level 1 in both the single and multiple location conditions, and there would be the same number of observations in these cells as in the other fan level cells, there were four sentences in which both the object and the location concept had only one association each (Fan Level 1). Arbitrarily, two of these sentences were assigned to the Single Location condition and two to the Multiple Locations condition.

For the recognition task, the studied probe sentences were those that were learned during the first part of the study. Nonstudied probes were generated by re-pairing the objects and locations from within the same cell of the design based on the number of associations for the object and location concepts. For example, using Fig. 1 as a guide, if two studied sentences were "The welcome mat is in the movie theater" and "The cola machine is in the public library," then the corresponding nonstudied probes would be "The welcome mat is in the public library" and "The cola machine is in the movie theater." This method of creating the nonstudied probes avoids the possibility that people will use plausibility judgments (Reder \& Anderson, 1980) to make the recognition decisions. Because the same numbers of associations were present for the nonstudied sentences, they were assigned to the Single Location and Multiple Locations conditions, as appropriate, and were analyzed as such.

Procedure The initial part of the study involved having people memorize the study sentences. This was done using a study-test procedure. During the study part, each sentence was presented on a computer screen, one at a time, for $7 \mathrm{~s}$ each. The sentences were shown in black letters on a white background using 20-point Courier font. People were asked to memorize the sentences as efficiently as possible.
During the test part of the memorization period, questions of the form "Where is the object?" and "What is in the location?" were given for each object and location, respectively. People typed their answers into the computer. For some questions, there were multiple answers, and people were told to provide all of them. For each question, a number was displayed indicating how many answers there were for that question (one, two, or three). After people typed in their answers, the computer indicated whether they were correct. If any of those answers were incorrect, the correct answers were shown for $3 \mathrm{~s}$ for each answer. The computer reported to the participant the number of correct answers at the end of the test part. Afterward, the program returned to the study part of memorization where all 18 sentences were studied again. This study-test procedure continued until all of the test questions were answered correctly for two complete sets of questions.

After sentence memorization, the recognition test was administered immediately, 1 h, 1 day, 1 week, or 2 weeks later. For this task, the memory probes were the 18 studied sentences and the 18 nonstudied sentences. Each of these sentences was presented in each of eight blocks of trials for a total of 288 probe sentences. People indicated that a probe was studied by pressing the left button on a computer mouse, which was marked with a "Y" for "yes, this sentence was studied." In comparison, people indicated nonstudied sentences by pressing the right button, which was marked with an "N" for "no, this sentence was not studied." People were told to respond as quickly and as accurately as possible. If a person responded incorrectly, the computer presented a message box, for $1 \mathrm{~s}$, that read either “**Error! Sentence true!**” or "**Error! Sentence not true!**," whichever was appropriate.

To familiarize people with the recognition test procedure, an 18-trial practice period was given after memorization and prior to the recognition test itself. During this time, the computer displayed lines that read either "sentence studied" or "sentence not studied," and people responded accordingly.

\section{Results}

We first consider the results of the learning rate data, followed by the critical response time data analysis. After this, there is an analysis of the accuracy data along with an analysis of the forgetting curves.

Learning People took three to ten study-test learning cycles to memorize the sentences $(M=4.78, S E=.083)$. The number of learning cycles did not vary among the various retention groups, $F<1$.

Response times For the response-time data, in addition to excluding any response times from incorrect trials, we also 


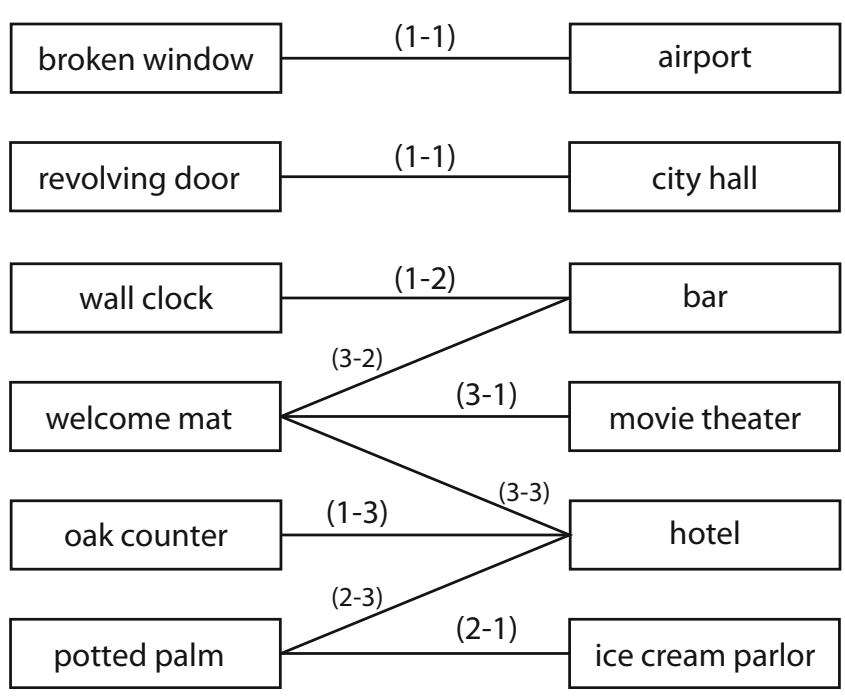

Fig. 1 Illustration of the study list design for the experiment in terms of the associations between the object and location concepts. The associative conditions are in parentheses, with the sentences that do not directly contribute to the Single Location and Multiple Location conditions in a

trimmed these data. First we excluded any response times faster than $200 \mathrm{~ms}$ and slower than $10,000 \mathrm{~ms}$ as being impossibly fast or exceedingly long. Then, we used Van Selst and Jolicoeur's (1994) criteria to trim the data of outliers as a

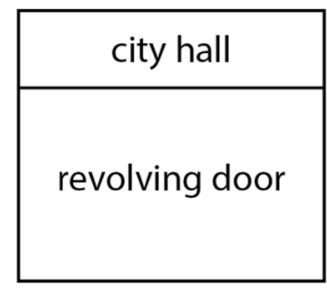

\begin{tabular}{|c|}
\hline ice cream parlor \\
\hline potted palm \\
\hline
\end{tabular}

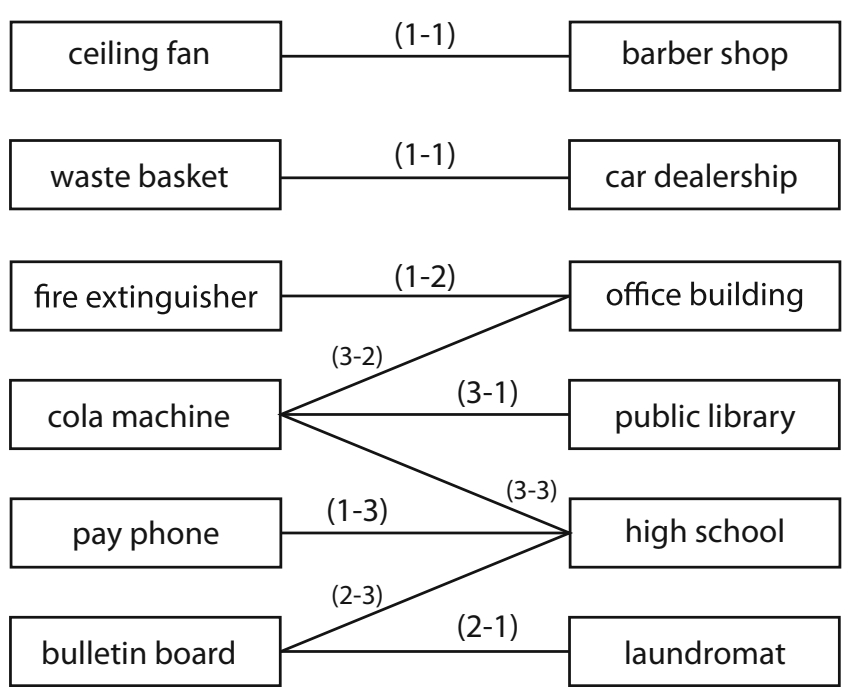

smaller typeface. $X-Y$ refers to $\mathrm{X}$ number of associations with the object and $Y$ number of associations with the location. Note that the particular assignment of objects and locations to the specific cells of the design were randomized for each participant

function of the sample size for a person, which preserves the overall proportion of data in question. This process resulted in $2.7 \%$ of the response-time data being dropped from the analysis. The response-time data, shown in Fig. 3 and Table 1,

\begin{tabular}{|l|}
\hline barber shop \\
\hline ceiling fan \\
\hline
\end{tabular}

\begin{tabular}{|c|}
\hline car dealership \\
\hline waste basket \\
\hline
\end{tabular}

\begin{tabular}{|c|}
\hline laundromat \\
\hline bulletin board \\
\hline
\end{tabular}

\begin{tabular}{|c|}
\hline bar \\
\hline wall clock \\
welcome mat \\
\hline
\end{tabular}

\begin{tabular}{|c|}
\hline movie theater \\
\hline welcome mat \\
\hline
\end{tabular}

\begin{tabular}{|c|}
\hline high school \\
\hline pay phone \\
bulletin board \\
cola machine \\
\hline
\end{tabular}

\begin{tabular}{|c|}
\hline public library \\
\hline cola machine \\
\hline
\end{tabular}

Fig. 2 Illustration of the study list design for the experiment in terms of the likely resulting event models. Note that the particular assignment of objects and locations to the specific cells of the design were randomized for each participant 
Immediate

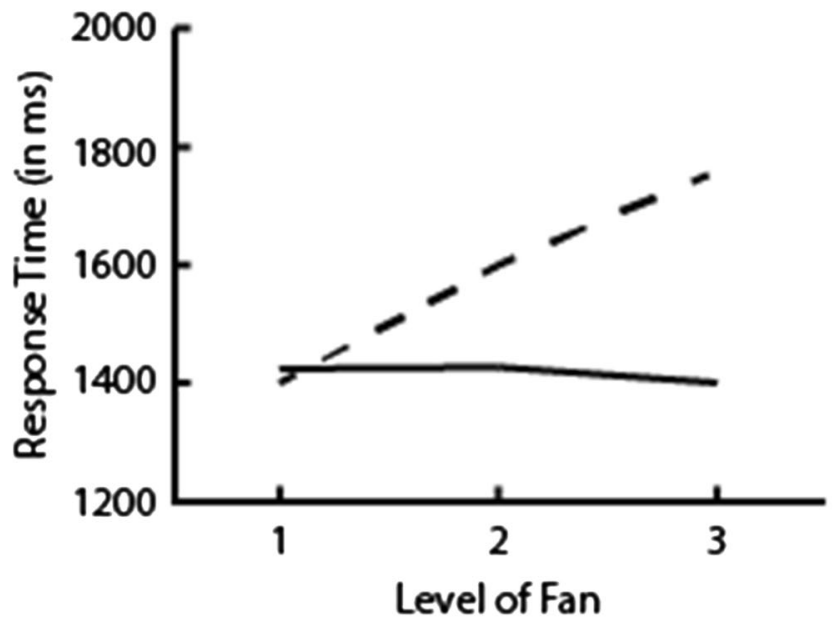

1 Day

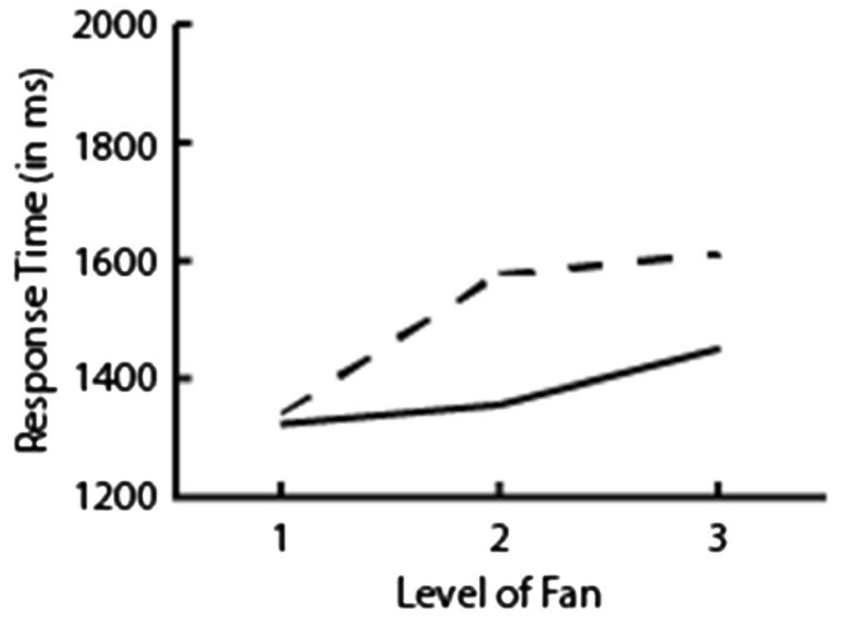

2 Weeks

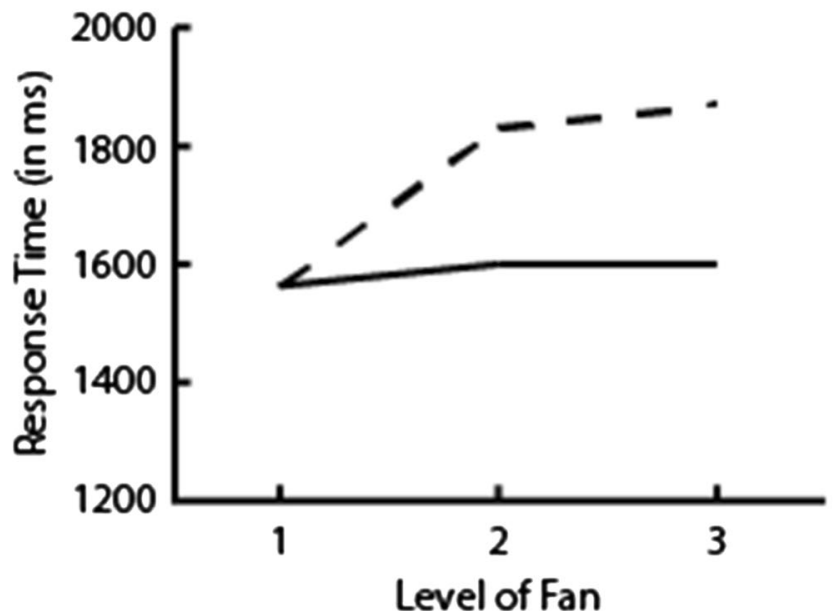

Fig. 3 Response time data for the various retention intervals
1 Hour

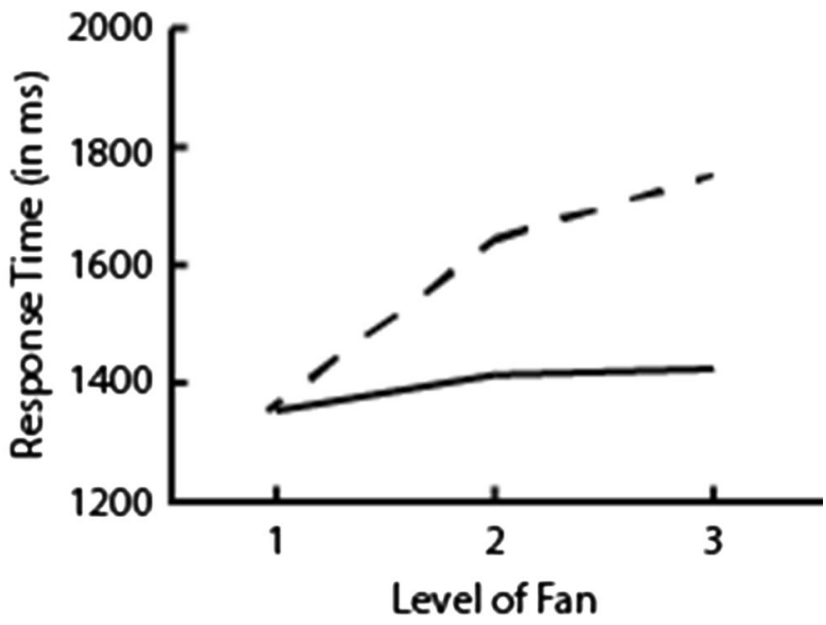

1 Week

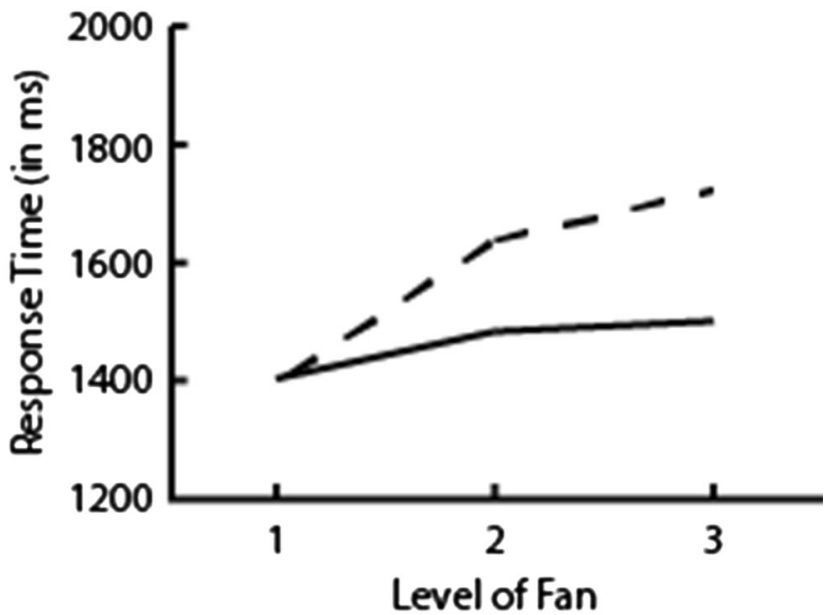

- - - Multiple Location Single Location 
Table 1 Response time and error rate data in each cell of the design for the Single and Multiple Location conditions, along with the other three cells of the design that did not directly contribute to these two conditions (standard errors are in parentheses)

Immediate testing

\begin{tabular}{|c|c|c|c|c|c|c|c|c|c|c|}
\hline & & \multicolumn{3}{|c|}{ Single location } & \multicolumn{3}{|c|}{ Multiple location } & \multicolumn{3}{|l|}{ Other cells } \\
\hline & & $1-1$ & $1-2$ & $1-3$ & $1-1$ & $2-1$ & $3-1$ & $2-3$ & $3-2$ & $3-3$ \\
\hline \multirow[t]{2}{*}{ Response time } & Studied & $1,365(61)$ & $1,379(66)$ & $1,350(63)$ & $1,367(57)$ & $1,471(62)$ & $1,685(83)$ & 1,617 (79) & 1775 (69) & $1705(72)$ \\
\hline & Nonstudied & $1,481(60)$ & $1,478(62)$ & 1,447 (49) & $1,443(58)$ & $1,730(88)$ & $1,821(88)$ & $1,668(70)$ & 2053 (97) & $1952(85)$ \\
\hline \multirow[t]{2}{*}{ Error rate } & Studied & $.03(.01)$ & $.03(.01)$ & $.02(.01)$ & $.03(.01)$ & $.04(.01)$ & $.06(.01)$ & $.06(.01)$ & $.07(.01)$ & $.05(.01)$ \\
\hline & Nonstudied & $.03(.01)$ & $.02(.01)$ & $.02(.01)$ & $.02(.01)$ & $.03(.01)$ & $.05(.01)$ & $.02(.01)$ & $.07(.02)$ & $.05(.02)$ \\
\hline \multicolumn{11}{|l|}{ 1-h delay } \\
\hline \multirow[t]{2}{*}{ Response time } & Studied & $1,352(53)$ & $1,350(50)$ & $1,356(60)$ & $1,342(58)$ & $1,563(77)$ & $1,648(82)$ & $1,629(67)$ & $1,784(79)$ & $1,869(87)$ \\
\hline & Nonstudied & $1,371(51)$ & $1,490(64)$ & $1,513(65)$ & $1,406(58)$ & $1,739(75)$ & $1,856(97)$ & $1,606(67)$ & $1,927(85)$ & 1,943 (112) \\
\hline \multirow[t]{2}{*}{ Error rate } & Studied & $.04(.01)$ & $.03(.01)$ & $.03(.01)$ & $.05(.01)$ & $.03(.01)$ & $.04(.01)$ & $.08(.01)$ & $.08(.02)$ & $.06(.01)$ \\
\hline & Nonstudied & $.04(.01)$ & $.02(.01)$ & $.05(.02)$ & $.04(.01)$ & $.07(.01)$ & $.09(.02)$ & $.03(.01)$ & $.06(.02)$ & $.07(.02)$ \\
\hline \multicolumn{11}{|l|}{ 1-day delay } \\
\hline \multirow[t]{2}{*}{ Response time } & Studied & $1,272(63)$ & $1,274(40)$ & $1,375(66)$ & $1,294(69)$ & $1,497(58)$ & $1,471(54)$ & $1,653(84)$ & $1,623(70)$ & $1,684(70)$ \\
\hline & Nonstudied & $1,377(52)$ & $1,435(46)$ & $1,523(71)$ & $1,386(59)$ & $1,662(64)$ & $1,755(72)$ & $1,667(78)$ & $1,952(83)$ & $1,894(81)$ \\
\hline \multirow[t]{2}{*}{ Error rate } & Studied & $.03(.01)$ & $.03(.01)$ & $.02(.01)$ & $.03(.01)$ & $.03(.01)$ & $.05(.01)$ & $.07(.01)$ & $.07(.01)$ & $.09(.02)$ \\
\hline & Nonstudied & $.05(.01)$ & $.03(.01)$ & $.04(.01)$ & $.06(.01)$ & $.04(.01)$ & $.08(.02)$ & $.05(.01)$ & $.10(.02)$ & $.11(.03)$ \\
\hline \multicolumn{11}{|l|}{ 1-week delay } \\
\hline \multirow[t]{2}{*}{ Response time } & Studied & $1,353(84)$ & $1,404(69)$ & $1,355(70)$ & $1,302(45)$ & $1,519(76)$ & $1,568(76)$ & $1,636(60)$ & $1,794(68)$ & $1,756(80)$ \\
\hline & Nonstudied & $1,453(61)$ & $1,557(67)$ & $1,638(89)$ & $1,484(69)$ & $1,743(71)$ & $1,861(84)$ & $1,739(75)$ & 2,098 (115) & $1,908(83)$ \\
\hline \multirow[t]{2}{*}{ Error rate } & Studied & $.02(.01)$ & $.03(.01)$ & $.03(.01)$ & $.03(.01)$ & $.03(.01)$ & $.07(.01)$ & $.08(.01)$ & $.11(.02)$ & $.08(.02)$ \\
\hline & Nonstudied & $.03(.01)$ & $.04(.01)$ & $.05(.01)$ & $.02(.01)$ & $.06(.02)$ & $.10(.20)$ & $.08(.01)$ & $.13(.03)$ & $.12(.02)$ \\
\hline \multicolumn{11}{|l|}{ 2-week delay } \\
\hline \multirow[t]{2}{*}{ Response time } & Studied & $1,538(84)$ & $1,488(76)$ & $1,497(80)$ & $1,485(82)$ & $1,708(87)$ & $1,705(96)$ & $1,751(96)$ & $1,817(103)$ & $1,825(110)$ \\
\hline & Nonstudied & $1,569(93)$ & $1,677(88)$ & $1,688(92)$ & $1,639(95)$ & $1,920(104)$ & $1,998(101)$ & $1,915(122)$ & $2,235(130)$ & 2,128 (133) \\
\hline \multirow[t]{2}{*}{ Error rate } & Studied & $.07(.02)$ & $.08(.02)$ & $.07(.02)$ & $.06(.01)$ & $.10(.02)$ & $.10(.02)$ & $.17(.03)$ & $.18(.03)$ & $.14(.02)$ \\
\hline & Nonstudied & $.08(.02)$ & $.12(.02)$ & $.15(.03)$ & $.08(.02)$ & $.15(.03)$ & $.19(.03)$ & $.20(.03)$ & $.17(.03)$ & $.22(.03)$ \\
\hline
\end{tabular}

were submitted to a 5 (Delay) $\times 2$ (Studied/Nonstudied) $\times 2$ (Condition) $\times 3$ (Fan) mixed ANOVA, with the first variable being between participants, and the rest within. ${ }^{2}$

First, as seen in previous studies, people responded faster to probes in the Single Location condition $(M=1,447 \mathrm{~ms})$ than to probes in the Multiple Location condition $(M=1,602 \mathrm{~ms})$, as supported by a main effect of Condition, $F(1,195)=126.52$, $M S E=114,340, p<.001, \eta_{p}^{2}=.39$. Also, people responded more slowly the greater the increase in fan (fan levels $1=1,414$; $2=1,554 ; 3=1,606 \mathrm{~ms}$ ), as revealed by the main effect of Fan, $F(2,390)=62.60, M S E=125,736, p<.001, \eta_{p}{ }^{2}=.24$. Importantly, the interference effect was much larger in the Multiple Location condition (fan levels $1=1,415 ; 2=1,655 ; 3$ $=1,737 \mathrm{~ms}$ ) than in the Single Location condition (fan levels $1=$

\footnotetext{
${ }^{2}$ Note that some of the data involve cells in which there were multiple associations with both the object and location concepts. Although these data are not relevant for the theoretical issues explored here, they are presented, for the sake of completeness, in the Appendix.
}

$1,413 ; 2=1,454 ; 3=1,475 \mathrm{~ms})$. There was a significant Condition $\times$ Fan interaction, $F(2,390)=39.58, M S E=94,364$, $p<.001, \eta_{p}{ }^{2}=.17$, and simple effects tests revealed that there was a fan effect for both the Single Location and Multiple Location Conditions, $F(2,390)=4.55, M S E=84,537, p=.01$, $\eta_{p}{ }^{2}=.02$, and $F(2,390)=77.40, M S E=85,997, p<.001, \eta_{p}{ }^{2}=$ .28 , respectively, although, again, clearly much larger for the Multiple Location condition.

Note that, of critical importance here, while overall response times at longer delays were somewhat slower, as revealed by the trend toward significance for the main effect of Delay, $F(4,195)=2.09, M S E=1,491,451, p=.08, \eta_{p}{ }^{2}=.04$, none of the interactions involving Delay were significant, including the more important Delay $\times$ Condition, Delay $\times$ Fan, and Delay $\times$ Condition $\times$ Fan interactions, $F<1, F<1$, and $F(8,390)=1.02, M S E=94,364, p=.36, \eta_{p}{ }^{2}=.02$, respectively. Thus, the basic pattern of retrieval, reflecting the organization of information into event models, was preserved over a period of 2 weeks, with perhaps only very small and minor 
changes that cannot be detected here. Although such effects might be detectable with a boost in power, they would remain very small effects.

In addition to the effects of primary interest, people responded faster to studied probes $(M=1,444 \mathrm{~ms})$ than to nonstudied probes $(M=1,605 \mathrm{~ms})$, as shown by the main effect of Studied/Nonstudied, $F(1,195)=166.70$, $M S E=92,451, p<.001, \eta_{p}{ }^{2}=.46$. In addition, the size of the difference between the Single Location and Multiple Location conditions was smaller for the studied probes $($ Single Location $=1,381 ;$ Multiple Location $=1,508 \mathrm{~ms})$ than for the nonstudied probes (Single Location $=1,513$; Multiple Location $=1,696 \mathrm{~ms}$ ), as there was a significant Studied/Nonstudied $\times$ Condition interaction, $F(1,195)=$ $6.24, M S E=73918, p=.01, \eta_{p}{ }^{2}=.03$, although this was a small effect. Simple effects tests revealed that the effect of Condition was significant for both the Studied and Nonstudied probes, $F(1,195)=79.42, M S E=61454, p<$ $.001, \eta_{p}{ }^{2}=.29$, and $F(1,195)=79.23, M S E=126805, p<$ $.001, \eta_{p}{ }^{2}=.29$, respectively. Finally, the size of the fan effect was smaller for studied probes (fan levels $1=$ $1,367 ; 2=1,465 ; 3=1,501 \mathrm{~ms})$ than for nonstudied probes (fan levels $1=1,461 ; 2=1,644 ; 3=1,710 \mathrm{~ms}$ ), as revealed by a significant Studied/Nonstudied $\times$ Fan interaction, $F(2,390)=14.22, M S E=49,981, p<.001, \eta_{p}{ }^{2}=$ .07 , with the fan effect being significant for both Studied, $F(2,390)=21.47, M S E=89,720, p<.001, \eta_{p}{ }^{2}=.10$, and Nonstudied probes, $F(2,390)=77.40, M S E=85,997, p<$ $.001, \eta_{p}{ }^{2}=.28$. Note that this difference in the pattern of response times and error rates (described in the next section) for the studied and nonstudied sentences parallels that reported in most previous studies of the differential fan effect, as well as studies of the fan effect itself. This pattern of greater fan effects for the nonstudied probes likely results from the general slowing that is seen when people make negative responses, along with the fact that more event models are involved (those involved for the object concept plus those involved for the location concept). This carries over to the error rate data as well.

Error rates The error rate data are shown in Fig. 4 and Table 1. The first thing to note is that, overall, the error rates were very low. This is not surprising given how well the material was learned. These data were also submitted to a 5 (Delay) $\times 2($ Studied/Nonstudied $) \times 2($ Condition $) \times$ 3 (Fan) mixed ANOVA. Of primary interest, people made fewer errors in response to Single Location probes $(M=$ $.04)$ than to Multiple Location probes $(M=.06)$, as supported by the main effect of Condition, $F(1,195)=30.79$, $M S E=.005, p<.001, \eta_{p}{ }^{2}=.14$. Also, people made more errors the greater the increase in fan (fan levels $1=.04 ; 2$ $=.05 ; 3=.06)$, as revealed by the main effect of Fan, $F(2,390)=21.88, M S E=.005, p<.001, \eta_{p}{ }^{2}=.10$.
Importantly, the Condition $\times$ Fan interaction was significant, $F(2,390)=8.22, M S E=.005, p<.001, \eta_{p}{ }^{2}=.04$. Simple effects tests revealed that there was a fan effect for the Multiple Location Condition, $F(2,390)=23.73$, MSE $=.006, p<.001, \eta_{p}{ }^{2}=.11$, but not for the Single Location condition, $F(2,390)=1.61, M S E=.004, p=.20, \eta_{p}{ }^{2}=$ .01 , consistent with a location-based organization of the information into event models.

Unlike the response time data, people generally made more errors the more time that had elapsed, as revealed by the main effect of Delay, $F(4,195)=14.88, M S E=.028, p<.001, \eta_{p}{ }^{2}=$ .23. Importantly, and like the response time data, the Delay $x$ Condition and Delay $\times$ Condition $\times$ Fan interactions were not significant, both $F_{\mathrm{s}}<1$. Thus, the basic pattern of retrieval, reflecting the organization of information into event models, was preserved over a period of 2 weeks. Apart from this, there was a significant Delay $\times$ Fan interaction, $F(8,390)=4.58$, $M S E=.005, p<.001, \eta_{p}{ }^{2}=.09$, with the size of the fan effect largely increasing with increased delays. The fan effect was not significant with immediate testing (fan levels $1=.03 ; 2=$ $.03 ; 3=.03$ ), $F<1$, or a day later (fan levels $1=.04 ; 2=.03 ; 3$ $=.05), F(2,78)=2.30, M S E=.003, p=.11, \eta_{p}{ }^{2}=.06$, but it was an hour later (fan levels $1=.04 ; 2=.04 ; 3=.05), F(2,78)$ $=3.18, M S E=.003, p=.047, \eta_{p}{ }^{2}=.08$, a week later (fan levels $1=.03 ; 2=.04 ; 3=.06), F(2,78)=12.49, M S E=.005$, $p<.001, \eta_{p}{ }^{2}=.24$, and 2 weeks later (fan levels $1=.07 ; 2=$ $.11 ; 3=.13), F(2,78)=11.25, M S E=.011, p<.001, \eta_{p}{ }^{2}=.22$.

In addition to the effects of primary interest, people made fewer errors in response to Studied probes $(M=.04)$ than to Nonstudied probes $(M=.06)$, as revealed by the main effect of Studied/Nonstudied, $F(1,195)=26.54, M S E=.007, p<.001$, $\eta_{p}{ }^{2}=.12$. There was also a significant Studied/Nonstudied $\times$ Fan interaction, $F(2,390)=6.93, M S E=.005, p=.001, \eta_{p}{ }^{2}=$ .03 , with the size of the fan effect being smaller for Studied probes (fan levels $1=.04 ; 2=.04 ; 3=.05$ ) than for Nonstudied probes (fan levels $1=.05 ; 2=.06 ; 3=.08$ ). It was just short of significant for the Studied probes, $F(2,390)=$ 3.004, MSE $=.004, p=.05, \eta_{p}{ }^{2}=.02$, and significant for the Nonstudied probes $F(2,390)=21.15, M S E=.006, p<.001$, $\eta_{p}{ }^{2}=.10$.

In terms of the retention interval, there was a significant Delay $\times$ Studied/Nonstudied interaction, $F(4,195)=5.62$, $M S E=.007, p<.001, \eta_{p}{ }^{2}=.10$, with size of the difference in number of errors between the Studied and Nonstudied probes not being different at short delays, but becoming significant, and generally growing larger, at longer delays. The difference was not significant at immediate testing (Studied $=$ .03 ; Nonstudied $=.03$ ),$F<1$, but was an hour later (Studied $=$ .04 ; Nonstudied $=.05), F(1,39)=5.96, M S E=.004, p=.02$, $\eta_{p}{ }^{2}=.13$, a day later (Studied $=.03$; Nonstudied $=.05$ ), $F(1,39)=9.93, M S E=.004, p=.003, \eta_{p}{ }^{2}=.20$, a week later $($ Studied $=.04 ;$ Nonstudied $=.05), F(1,39)=5.15, M S E=$ $.005, p=.03, \eta_{p}{ }^{2}=.12$, and 2 weeks later (Studied $=.08$; 

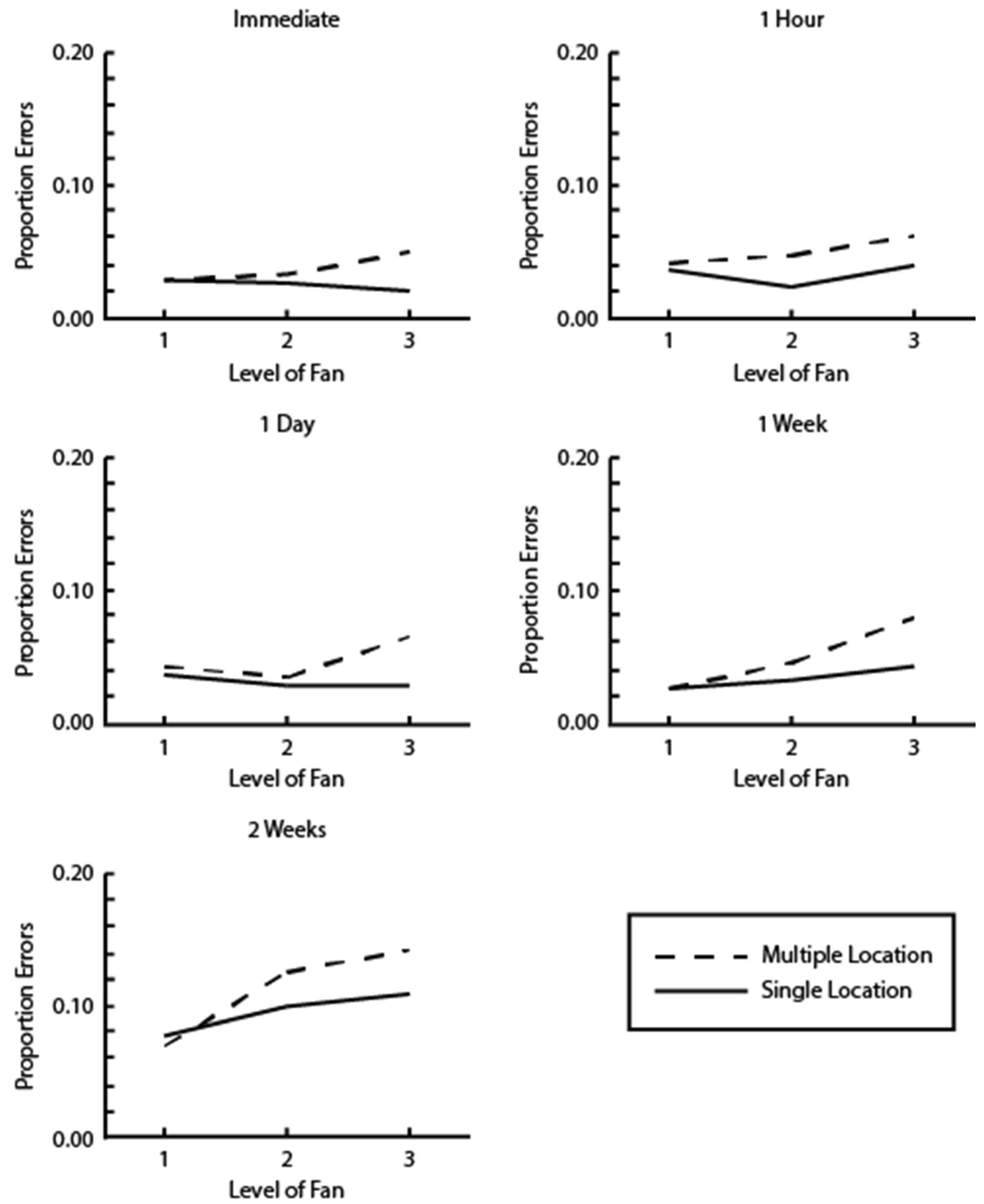

- - Multiple Location

Single Location

Fig. 4 Error rate data for the various retention intervals 
Nonstudied $=.13), F(1,39)=14.98, M S E=.017, p<.001, \eta_{p}^{2}$ $=.28$.

Finally, there was also a just significant Delay $\times$ Studied/ Nonstudied $\times$ Fan interaction, $F(8,390)=1.99, M S E=.005, p$ $=.047, \eta_{p}{ }^{2}=.04$. This was broken down by looking at the Studied/Nonstudied $\times$ Fan interactions at each delay. This interaction was not significant immediately, $F<1$, a day later, $F(2,78)$ $=1.76, M S E=.003, p=.18, \eta_{p}{ }^{2}=.04$, or a week later, $F(2,78)=$ $1.16, M S E=.005, p=.32, \eta_{p}{ }^{2}=.03$, but was an hour later, $F(2,78)=3.28, M S E=.004, p=.043, \eta_{p}^{2}=.08$, and 2 weeks later, $F(2,78)=4.84, M S E=.010, p=.010, \eta_{p}{ }^{2}=.11$. Given the absence of a clear pattern, how small this effect is, and how tangential these interactions are to the primary issues at hand, we do not attempt to explain this particular pattern of data.

Forgetting curve In addition to looking at the differential fan effect in the response time and error rate data, we also assessed the forgetting curve for this data set. As noted earlier, over a century of research has shown that over time, memory performance will show a negatively accelerating forgetting curve in which most of the forgetting occurs soon after learning. We assessed whether a similar pattern would be observed for the current study.

To address the significant main effect of Delay, we first collapsed performance across all of the conditions within a retention interval. This function is shown in Fig. 5. As can be seen, the pattern of data does not conform to the normal forgetting curve function. Instead, as can be seen, memory is very good, with little forgetting, and then the rate of forgetting increases over time. Thus, this is a positively, rather than a negatively, accelerating function, with some change occurring at the 1-week interval, but most of the change occurring at the 2 -week interval. Comparisons revealed significant differences between the Immediate and 1-week retention interval, $F(1,78)$ $=4.87, M S E=.001, p=.03, \eta_{p}{ }^{2}=.06$, as well as between the 2 -week interval and all of the others, all $p s<.001$. This may be due to a number of potential factors compared to other studies of the forgetting curve. These include: (a) the material was overlearned, (b) a recognition test was used rather than recall, (c) relearning during the recognition test may be obscuring the pattern of forgetting, and (d) these data reflect the retrieval of information from event models. Each of these possibilities is considered in more detail in the General discussion.

Finally, in addition to the main effect of delay, there were also significant Delay $\times$ Studied/Nonstudied, Delay $\times$ Fan, and Delay $\times$ Studied/Nonstudied $\times$ Fan interactions. To address these interactions, we plotted the data for each fan level separately for the studied and nonstudied probes at each delay. As can be seen in Fig. 6, all of the curves showed the same basic positively accelerated functions, with the nonstudied fan level 2 and 3 probes showing a greater increase in forgetting at the 1-week and 2-week retention intervals. Thus, the increased

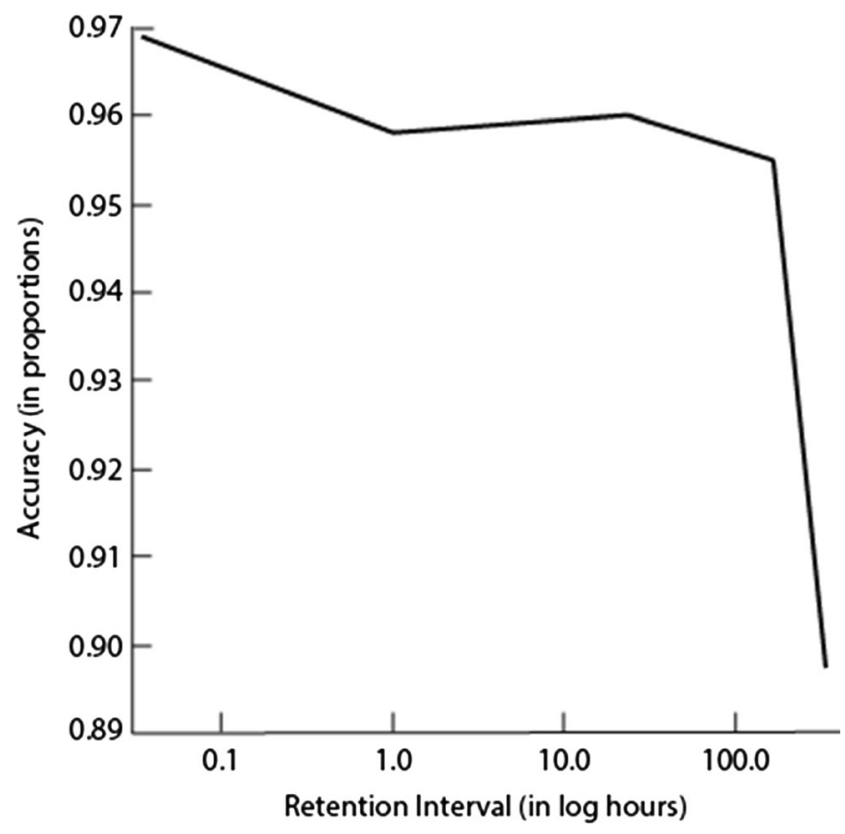

Fig. 5 Overall accuracy rate data for the various retention intervals

forgetting that is observed in these data is due more to those items that were more susceptible to retrieval interference.

\section{General discussion}

The current study provides insight into the influence of very long retention intervals on the associative interference effects and the organization of information into event models, as revealed by the differential fan effect. It also provided an
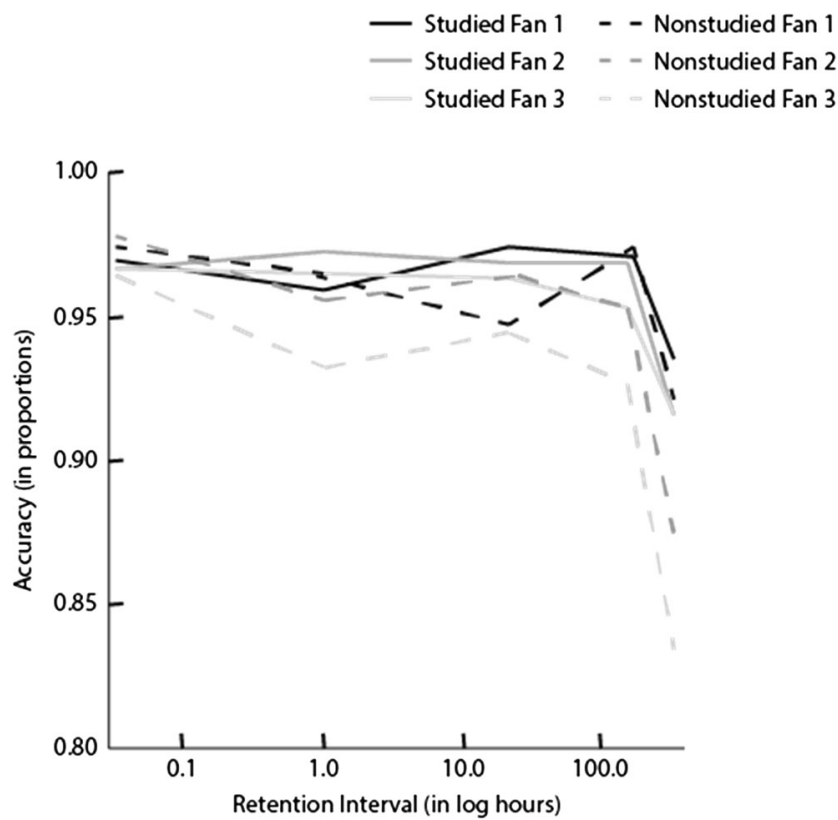

Fig. 6 Accuracy rate data breakdown for the different fan levels for studied and nonstudied probes for the various retention intervals 
opportunity to assess the forgetting curve in this experimental paradigm. Each of these topics is considered in the following two sections.

Differential fan effect. The current experiment aimed to assess how the differential fan effect would be altered by longer retention intervals. Three possibilities were considered. These were: (a) a decline in interference, which would facilitate recognition primarily in the Multiple Location condition, (b) an emergence of interference as event models split apart, which would hinder recognition primarily in the Single Location condition, and (c) that the organization of information into event models would persist over longer retention intervals, and the differential fan effect would be largely unaffected. The results revealed that, overall, the segregation and organization of information into location-based event models remained stable even over a 2-week long retention interval, at least with our paradigm. Some of this may be due to the overlearning of some of the items or to our repeated testing paradigm, although we think that this is unlikely. This is consistent with other research (e.g., Kintsch et al., 1990) showing that event models can be retained for very long periods of time. Information in the Single Location condition, which can easily be integrated into a single event model, remained integrated and showed no evidence of retrieval inference in the response time data.

The research on human memory is replete with examples of how memories change over time. For example, people are likely to introduce distortions into their memories to make them more schema consistent (e.g., Bartlett, 1932), the probability of creating false memories increases (e.g., Seamon et al., 2002), and, overall, more and more information is forgotten as time progresses (e.g., Ebbinghaus, 1885). However, in spite of this, it is also thought to be the case that as more time passes, information becomes more consolidated and resistant to forgetting (Nadel \& Moscovitch, 1997; Ribot, 1882). What dictates what is forgotten and lost versus what will be consolidated and remembered is not clear at this time. While some well-known factors may play into this, such as frequency of rehearsal (e.g., Glenberg \& Lehmann, 1980), distinctiveness (e.g., Hunt, 1995), and taking tests rather than studying further (e.g., Carrier \& Pashler, 1992; Roediger \& Karpicke, 2006), many of these phenomena depend on materials that are highly unusual from our everyday experiences (e.g., The War of the Ghosts or word lists), or that our memories are not well tuned to learn given the amount of deep processing required to commit the materials to memory (e.g., expository texts).

At this point, we would suggest that, although it requires much more empirical verification, one of these factors influencing what is forgotten or remembered is the eventrelated nature of some information. Some casual thinking reveals that while people are awful when it comes to remembering lists of words or paired associates, they remember events much better, even in the absence of much effort on their part to memorize such information. Take the examples of autobiographical memories, television shows, and movie serials. We can often remember a large number of details from these experiences of events without much explicit effort at memorization. This is often effective enough to allow us to readily pick up the threads in our social interactions, the next season of a show, or a new movie in a series without much difficulty. For example, people may binge-watch the new episodes of a show on television, and then not see another episode for almost a year until the next season comes out. When this happens, although there is some forgetting of some details, the bulk of memory for the prior season is available so that many people readily understand what is going on. This is not to say that event memory is not aided by factors such as repeated rehearsal, distinctiveness, and being tested, but only to say that there is more going on here.

This current study involves event memory because the situations described in our study sentences are amenable to representation at an event model level of representation, and not merely propositions (Radvansky, 2005). Our response time data demonstrate that this level of representation persists and facilitates retrieval over periods of up to 2 weeks. Information that was integrated into a common event model continues to show retrieval patterns as if it were still integrated in that form. The event models maintain their structure. Moreover, information that is distributed across multiple events continues to show the interfering effects of related but irrelevant event models. Thus, people maintain information in event model structure for at least up to 2 weeks.

The two remaining theoretical possibilities are addressed next. As noted in the introduction, there is some evidence that at longer retention intervals, proactive and retroactive interference effects can grow smaller, particularly if sleep is involved (Abel \& Bäuml, 2014; Drosopoulos, et al., 2007; Ekstrand, 1967). Moreover, any such sleep-related influence would be repeated across multiple days. If this were the case, then it might be possible for the associative interference to also be reduced, thereby reducing and flattening out the fan effect. Thus, the prediction for this view was that the interference effects that were observed immediately, particularly in the Multiple Location condition, should have grown smaller, and perhaps vanished altogether. However, our results provide no support for this possibility.

The other theoretical possibility suggested is that the interference effects would grow larger. This could result over time as the event models that are stored in long-term memory start to come apart. This could happen either because the information bound together in long-term memory somehow becomes unbound, or because various components of otherwise intact event models are lost. Thus, the prediction for this view was that an interference effect that was not observed immediately, 
particularly for the Single Location condition, should have emerged with longer retention intervals. Moreover, this event model disintegration should have resulted in a reduction in the differential fan effect at longer retention intervals. However, our results do not strongly support this possibility.

One concern about this conclusion has to do with the error rate data. Specifically, while it was clear that the critical Condition $\times$ Fan interaction did not significantly change across the various retention intervals, there was an increase in the fan effect for the error rates in both the Single Location and Multiple Location conditions with increased retention intervals. Although this increase may suggest that the event models are starting to degrade over time, this would only have a minor influence after 2 weeks, given that there is no influence on the pattern of response times, and that the difference between the Single and Multiple Location conditions remained constant. Thus, the most that could be said for this possibility is that there are the beginnings of a breakdown in the event models stored in long-term memory, but that they have largely remained intact over a 2-week period. Perhaps greater evidence of further disintegration could be observed at longer retention intervals.

Forgetting curves In addition to the differential fan effect, which is of primary interest here, the results of the current study are also, secondarily, interesting in terms of understanding the forgetting curve for long-term memory. As noted earlier, the standard forgetting curve is a negatively accelerating function, with the greatest amount of forgetting occurring early on during retention, and the rate of forgetting tapering off after that. However, the accuracy data observed in our experiment showed the opposite pattern. There was very little forgetting initially, and then the rate of forgetting increased at longer delays. Four possibilities were suggested in the results section to account for this pattern of data. Each of these possibilities is considered here.

The first possibility is that the forgetting curve observed here is due to overlearning (Driskell, Copper, \& Willis, 1992). For the current study, the sentences could be considered overlearned in that the criterion for memorization was the ability to twice answer all of the study questions correctly. Thus, people were required to achieve a perfect criterion level of learning and then to continue to study beyond that. Moreover, most of those sentences were learned at the beginning of the memorization period and so would have received more than just a single overlearning trial after the memorization of that item. From a possible overlearning account, it could be that when a memory is overlearned, it becomes more resistant to forgetting. As a result, only the weakest memories would have been forgotten and, early on, only a small number would drop to the point where they would be forgotten. However, over time, more and more memories may be forgotten at an ever-increasing rate.
A consideration of the published data suggests that this is not a viable account. Specifically, research on overlearning has shown standard forgetting curves, although those curves may grow shallower with more overlearning (Krueger, 1929).

The second possible explanation for the observed forgetting function is that, rather than using a recall test, as is more typical of studies assessing the forgetting curve (e.g., Kristo, Janssen, \& Murre, 2009; Wixted \& Ebbesen, 1991), a recognition test was used. Perhaps what may be lost in recall tests is an ability to access information using processes that are not needed with recognition. With recognition there is no need to generate items or organize retrieval output. Moreover, recognition may allow for the retrieval of memories that are otherwise more weakly stored. That said, most studies using recognition that look at the retention of information over several time periods do not show the present pattern (e.g., McBride \& Dosher, 1997; Wickelgren, 1972), but instead show the typical forgetting curve. This is also true of the Kintsch et al. (1990) study discussed earlier. They used recognition to assess memory at the surface form, textbase, and event model levels. Normal forgetting curves were observed at the surface form and textbase levels, but not the event model level. Thus, there is not strong evidence to suggest that the use of a recognition test was sufficient to produce the observed forgetting curve.

The third possible explanation for the observed forgetting function is that this is not a reflection of memory and forgetting, it is rather a reflection of relearning that may have occurred during the recognition test. ${ }^{3}$ Specifically, the recognition test that we used involved providing feedback if a person made an incorrect response, and there were eight blocks of trials, with each item being tested eight times. Thus, if a person had forgotten a particular study sentence early on during recognition, the feedback would have corrected this memory error and performance would have improved. If so, it is possible that for the shorter retention intervals, a normal forgetting curve would have been observed if this relearning did not occur. The prediction of such an account is that if we were to look at the first block of trials, prior to any opportunity for relearning, then there would be a normal forgetting curve, and that the positively accelerating curve would emerge on the later blocks of trials.

This possibility was assessed by breaking the data down into blocks and analyzing performance as a function of block. An 8 (Block) $\times 5$ (Retention Interval) ANOVA did reveal a significant main effect of block, $F(7,1365)=4.51, M S E=$ $.002, p<.001, \eta_{p}{ }^{2}=.02$, with people performing more accurately overall on later blocks than earlier blocks, consistent with a relearning account. Note that this is not a problem for the primary analysis of the response times, which is aimed at the ease of retrieval, not the accuracy of retrieval. Moreover, the interaction was also significant, $F(28,1365)=4.05, M S E=$

\footnotetext{
${ }^{3}$ We would like to thank Tessa Warren for suggesting this possibility.
} 


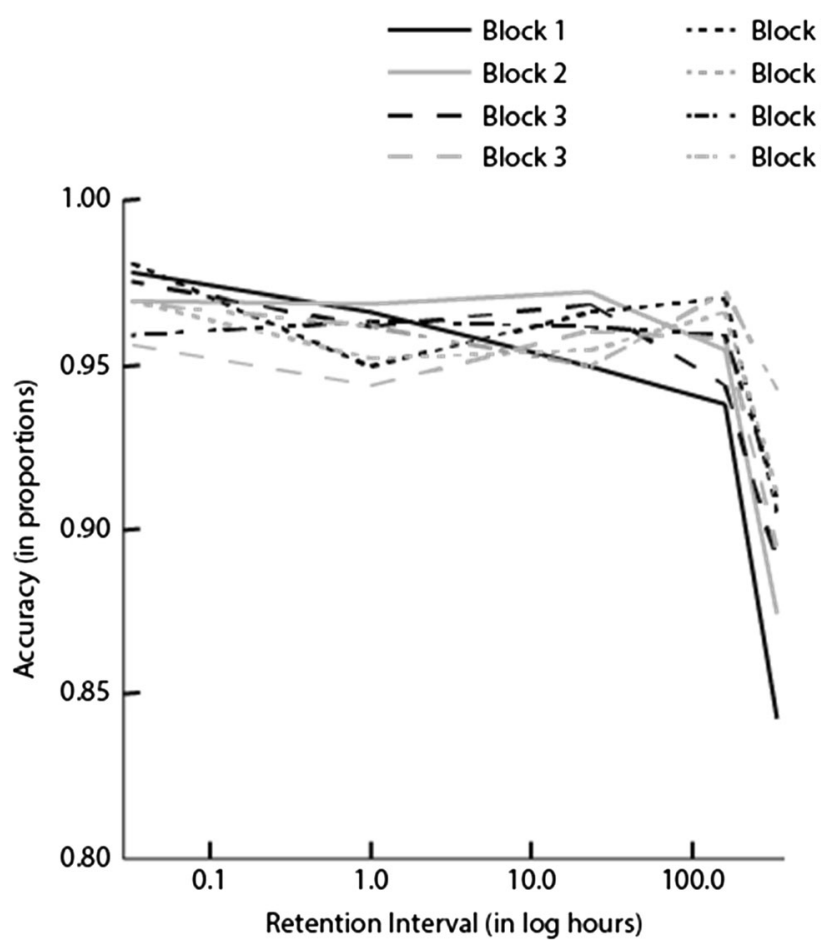

Fig. 7 Accuracy rate data per block at the various retention intervals. Note that the positively accelerated forgetting function is larger for the earlier blocks than the later blocks

$.002, p<.001, \eta_{p}{ }^{2}=.08$. The data across the different retention intervals for each of the recognition test blocks are shown in Fig. 7. What this shows is the opposite of a relearning account of the positively accelerating forgetting curve. Specifically, this pattern of data is most prominent on the first block of trials, and is reduced as the recognition test progresses. If anything, our recognition test procedure attenuated, rather than created, the positively accelerating forgetting function. Thus, we can confidently and safely reject this account of this forgetting curve pattern.

The fourth possibility is that this outcome may have something to do with the idea that people are using event models to make their recognition decisions. In most studies of memory and the forgetting curve, the materials used are relatively simplistic, such as individual words, unrelated pictures, nonsense syllables, and so on. However, in the current study, people were likely creating event models to capture the situations described by the memorized sentences, and then used these to make their recognition decisions (Radvansky \& Zacks, 1991). As previous work has shown, event models show very little to no forgetting over longer periods of time (Kintsch et al., 1990). Moreover, a number of elements of knowledge are combined to create an event model. Thus, if some component of it becomes weakened over time, the retrieval of the rest of the event model may activate these other components, thereby reinforcing them and forestalling forgetting. Over time, the proportion of the event model components that are lost becomes larger. As a result, there is a concomitant increase in the likelihood that the event model will be forgotten. While such a process is speculative at this point, it does provide predictions to allow future work to explore this pattern of forgetting in which the rate of forgetting starts out slowly and then picks up over time.

Note also that it is possible that the increased forgetting rate may not continue. It is possible that with even longer delays, the rate of forgetting would then slow down, much like the standard forgetting curve, thereby producing an S-shaped function. This could occur because, while there is some resistance to forgetting initially, at longer periods of time the process of forgetting that is typically used to describe memory retention begins to be observed. We think that this is a likely outcome. However, this possibility remains to be empirically verified.

\section{Conclusions}

The current study explored the influence of various retention intervals on the organization of information into event models and the impact this has on later memory retrieval. What was found was that this organization appears to be largely preserved, with some minor deviations, over a 2-week period. If anything is occurring at longer delays, people are more likely to make recognition test errors, but the pattern of performance indicative of integrated or segregated storage remains largely intact. A further, unexpected finding from this work was that the forgetting function that was observed appears to be positively rather than negatively accelerated. Based on a review of the literature, this does not appear to be due to overlearning, the use of recognition, or feedback during recognition. We suggest that this pattern of data may be due to the use of event models during memory retrieval.

\section{Appendix}

Results for data involving cells in which there are multiple associations with object and location concepts.

To provide a more complete account of the data, the results of response time and error rate analysis for the design cells that did not contribute to the Single and Multiple Location conditions are given here. These are shown in Table 1. These data were not included in that analysis because they involve multiple associations with both the object and location concepts. As such, they do not neatly fit into the single and multiple location conditions. These were used in the study list design to provide the appropriate number of associations for the object and location sentences, while keeping the number of study sentences small and the experiment manageable. For these analyses, the cells are referred to in terms of the number of 
associations with the object and location concepts. So, for example, 2-3 means that the objects were in two locations, and the locations each had three objects associated with them.

First, the response time data were submitted to a 5 (Delay) $\times 2$ (Studied/Nonstudied) $\times 3$ (Condition) mixed ANOVA . This analysis revealed a significant effect of Studied/ Nonstudied, $F(1,195)=62.54, M S E=163,172, p<.001$, $\eta_{p}{ }^{2}=.24$, with people responding faster to Studied ( $M=$ $1,728 \mathrm{~ms})$ than to Nonstudied probes $(M=1,912 \mathrm{~ms})$. There was also a main effect of Condition, $F(2,390)=42.82, M S E=$ $125,541, p<.001, \eta_{p}{ }^{2}=.18$, with people responding faster to the 2-3 probes $(M=1,688 \mathrm{~ms})$, than to the $3-2(M=1,906$ $\mathrm{ms})$ or 3-3 probes $(M=1,867 \mathrm{~ms})$. There was also a significant Studied/Nonstudied $\times$ Condition interaction, $F(2,390)=$ 12.86, MSE $=106,023, p<.001, \eta_{p}{ }^{2}=.06$. A simple effects test revealed that the effect of Condition was significant for the Studied probes, $F(2,390)=8.64, M S E=87,041, p<.001, \eta_{p}{ }^{2}$ $=.04$, as well as the Nonstudied probes, $F(2,390)=21.43$, $M S E=144,523, p<.001, \eta_{p}{ }^{2}=.18$, although the size of the effect is clearly larger for the Nonstudied probes. For the Studied probes, there were faster response times for the 2-3 probes $(M=1,657 \mathrm{~ms})$ than the $3-2(M=1,759 \mathrm{~ms}), F(1,195)$ $=10.42, M S E=98,616, p=.001, \eta_{p}{ }^{2}=.05$ and 3-3 probes $(M$ $=1,768 \mathrm{~ms}), F(1,195)=14.15, M S E=86,284, p<.001, \eta_{p}{ }^{2}=$ .07 , which did not differ from one another, $F<1$. Similarly, for the Nonstudied probes, there were faster response times for the $2-3$ probes $(M=1,719 \mathrm{~ms})$ than the $3-2(M=2,053 \mathrm{~ms})$, $F(1,195)=69.56, M S E=160,258, p<.001, \eta_{p}{ }^{2}=.26$ and $3-3$ probes $(M=1,965 \mathrm{~ms}), F(1,195)=49.85, M S E=121,160, p<$ $.001, \eta_{p}{ }^{2}=.10$, which just significantly differed from one another, $F(1,195)=5.11, M S E=152,151, p=.03, \eta_{p}{ }^{2}=.03$. Overall, this pattern of data is consistent with the analyses of the Single Location and Multiple Location conditions. Specifically, response times were slower the more locations that were involved, thereby producing more interference.

Finally, the Delay $\times$ Studied/Nonstudied interaction was just significant, $F(4,195)=2.45, M S E=163,172, p=.048$, $\eta_{p}{ }^{2}=.05$. The main effect of Delay was not significant for either the Studied probes, $F<1$, or the Nonstudied probes, $F(4,195)=1.65, M S E=836,607, p=.16, \eta_{p}{ }^{2}=.03$. Neither the main effect of Delay, nor any of the other interactions involving Delay, were significant, all $p \mathrm{~s}>.20$. Thus, once again, the retention interval did not have any major influences on the speed with which information was retrieved from memory as a function of the number of associations.

Next, the error rate analysis revealed a small significant main effect of Condition, $F(2,390)=3.90, M S E=.010, p=$ $.02, \eta_{p}^{2}=.02$, with people making fewer errors for the $2-3$ probes $(M=.09)$ than to the 3-2 $(M=.10)$ and 3-3 probes $(M$ $=.09$ ). Although the main effect of Studied/Nonstudied was not significant, $F<1$, there was a significant Studied/ Nonstudied $\times$ Condition interaction, $F(2,390)=6.13, M S E=$ $.009, p=.002, \eta_{p}{ }^{2}=.03$. Simple effects tests revealed that the effect of Condition did not reach significance for the Studied probes, $F(2,390)=2.31, M S E=.008, p=.10, \eta_{p}{ }^{2}=.01$, but did for the Nonstudied probes, $F(2,390)=6.88, M S E=.011, p$ $=.001, \eta_{p}{ }^{2}=.03$. For the Nonstudied probes, accuracy was higher for the $2-3$ probes $(M=.08)$ than the $3-2(M=.10)$, $F(1,195)=6.18, M S E=.011, p=.01, \eta_{p}^{2}=.03$ and 3-3 probes $(M=.11), F(1,195)=14.67, M S E=.009, p<.001$, $\eta_{p}{ }^{2}=.07$, which were not different from one another, $F(1,195)$ $=1.11, M S E=.011, p=.29, \eta_{p}{ }^{2}=.01$. This pattern of data is largely consistent with the response time analysis. Specifically, error rates were worse, at least for the nonstudied probes, the more locations that were involved, thereby producing more interference.

Unlike the response time data, there was a significant effect of Delay, $F(4,195)=21.23, M S E=.029, p<.001, \eta_{p}{ }^{2}=.30$. The error rates were .05 for the immediate group, .06 for the 1-h delay, .08 for the 1-day delay, .10 for the 1-week delay, and .18 for the 2 -week delay. All of the retention delays were significantly different from one another, $p \leq .009$, except for the differences between the Immediate and 1 -h delays, $F<1$, the 1-h and 1-day delays, $F(1,78)=2.24, M S E=.021, p=.14$, $\eta_{p}{ }^{2}=.03$, and the 1-day and 1-week delays, $F(1,78)=2.03$, $M S E=.019, p=.16, \eta_{p}{ }^{2}=.03$. Thus, performance largely worsened with longer delays, and the forgetting curve was positively accelerating, as with the primary analysis.

Finally, the Delay $\times$ Studied/Nonstudied interaction was just significant, $F(4,195)=2.49, M S E=.013, p=.045, \eta_{p}{ }^{2}$ $=.05$. The main effect of Delay was significant for both the studied probes, $F(4,195)=13.53, M S E=.015, p<.001, \eta_{p}{ }^{2}=$ .22 , and the Nonstudied probes, $F(4,195)=16.60, M S E=$ $.011, p<.001, \eta_{p}{ }^{2}=.26$. The error rates for the studied probes were .06 for the immediate group, .07 for the 1-h delay, .08 for the 1-day delay, .09 for the 1-week delay, and .17 for the 2week delay. In comparison, the error rates for the nonstudied probes were .05 for the immediate group, .05 for the 1-h delay, .09 for the 1-day delay, .11 for the 1-week delay, and .20 for the 2-week delay. Thus, at shorter delays there were more errors for the studied probes, whereas at longer delays there were more errors for the nonstudied probes, although these differences are small. When studied versus nonstudied comparisons were made at each of the retention intervals, none were found to be significant.

\section{References}

Abel, M., \& Bäuml, K. H. T. (2014). Sleep can reduce proactive interference. Memory, 22(4), 332-339. doi:10.1080/09658211.2013. 785570

Anderson, R. B. (2001). The power law as an emergent property. Memory \& Cognition, 29(7), 1061-1068. doi:10.3758/BF03195767

Anderson, R. B., \& Tweney, R. D. (1997). Artifactual power curves in forgetting. Memory \& Cognition, 25(5), 724-730. doi:10.3758/ BF03211315 
Averell, L., \& Heathcote, A. (2011). The form of the forgetting curve and the fate of memories. Journal of Mathematical Psychology, 55(1), 25-35. doi:10.1016/j.jmp.2010.08.009

Bartlett, F. C. (1932). Remembering: A study in experimental and social psychology. Cambridge University Press.

Bohay, M., Blakely, D. P., Tamplin, A. K., \& Radvansky, G. A. (2011). Note taking, review, memory, and comprehension. The American Journal of Psychology, 124(1), 63-73. doi:10.5406/amerjpsyc.124. 1.0063

Carrier, M., \& Pashler, H. (1992). The influence of retrieval on retention. Memory \& Cognition, 20(6), 633-642. doi:10.3758/BF03202713

Driskell, J. E., Copper, C., \& Willis, R. P. (1992). Effect of overlearning on retention. Journal of Applied Psychology, 77(5), 615-622. doi: 10.1037/0021-9010.77.5.615

Drosopoulos, S., Schulze, C., Fischer, S., \& Born, J. (2007). Sleep's function in the spontaneous recovery and consolidation of memories. Journal of Experimental Psychology: General, 136(2), 169183. doi:10.1037/0096-3445.136.2.169

Ebbinghaus, H. (1885/1913). Memory: A contribution to experimental psychology (H. A. Ruger \& C. E. Bussenius, Trans.). New York: Columbia University, Teacher's College. (Reprinted 1964, New York: Dover)

Ekstrand, B. R. (1967). Effect of sleep on memory. Journal of Experimental Psychology, 75(1), 64-72. doi:10.1037/h0024907

Fletcher, C. R., \& Chrysler, S. T. (1990). Surface forms, textbases, and situation models: Recognition memory for three types of textual information. Discourse Processes, 13(2), 175-190. doi:10.1080/ 01638539009544752

Glenberg, A. M., \& Lehmann, T. S. (1980). Spacing repetitions over 1 week. Memory \& Cognition, 8(6), 528-538. doi:10.3758/ BF03213772

Hunt, R. R. (1995). The subtlety of distinctiveness: What von Restorff really did. Psychonomic Bulletin \& Review, 2(1), 105-112. doi:10. 3758/BF03214414

Johnson-Laird, P. N. (1983). Mental Models: Towards a Cognitive Science of Language, Inference, and Consciousness. Cambridge, MA: Harvard University Press.

Kintsch, W., Welsch, D., Schmalhofer, F., \& Zimny, S. (1990). Sentence memory: A theoretical analysis. Journal of Memory and Language, 29(2), 133-159. doi:10.1016/0749-596X(90)90069-C

Kristo, G., Janssen, S. M., \& Murre, J. M. (2009). Retention of autobiographical memories: An Internet-based diary study. Memory, 17(8), 816-829. doi:10.1080/09658210903143841

Krueger, W. C. F. (1929). The effect of overlearning on retention. Journal of Experimental Psychology, 12(1), 71-78. doi:10.1037/h0072036

Manrique, T., Moron, I., Ballesteros, M. A., Guerrero, R. M., Fenton, A. A., \& Gallo, M. (2009). Hippocampus, aging, and segregating memories. Hippocampus, 19, 57-65. doi:10.1002/hipo.20481

McBride, D. M., \& Dosher, B. A. (1997). A comparison of forgetting in an implicit and explicit memory task. Journal of Experimental Psychology: General, 126(4), 371-392. doi:10.1037/0096-3445. 126.4.371

Meeter, M., \& Murre, J. M. (2004). Consolidation of long-term memory: evidence and alternatives. Psychological Bulletin, 130(6), 843-857. doi:10.1037/0033-2909.130.6.843

Murre, J. M., \& Chessa, A. G. (2011). Power laws from individual differences in learning and forgetting: mathematical analyses. Psychonomic Bulletin \& Review, 18(3), 592-597. doi:10.3758/ s13423-011-0076-y

Nadel, L., \& Moscovitch, M. (1997). Memory consolidation, retrograde amnesia and the hippocampal complex. Current Opinion in Neurobiology, 7(2), 217-227. doi:10.1016/S0959-4388(97)80010-4

Narvaez, D., Radvansky, G. A., Lynchard, N. A., \& Copeland, D. E. (2011). Are older adults more attuned to morally charged information? Experimental Aging Research, 37(4), 398-434. doi:10.1080/ 0361073X.2011.590756
Peterson, S. B., \& Potts, G. R. (1982). Global and specific components of information integration. Journal of Verbal Learning and Verbal Behavior, 21(4), 403-420. doi:10.1016/S0022-5371(82)90700-9

Radvansky, G. A. (1998). The organization of information retrieved from situation models. Psychonomic Bulletin \& Review, 5(2), 198-206. doi:10.3758/BF03212952

Radvansky, G. A. (1999). The fan effect: A tale of two theories. Journal of Experimental Psychology: General, 128(2), 563-579. doi:10. 1037/0096-3445.128.2.198

Radvansky, G. A. (2005). Situation models, propositions, and the fan effect. Psychonomic Bulletin \& Review, 12(3), 478-483. doi:10. 3758/BF03193791

Radvansky, G. A. (2009). Spatial directions and situation model organization. Memory \& Cognition, 37(6), 796-806. doi:10.3758/MC.37. 6.796

Radvansky, G. A. (2012). Across the event horizon. Current Directions in Psychological Science, 21(4), 269-272. doi:10.1177/ 0963721412451274

Radvansky, G. A., \& Copeland, D. E. (2004). Working memory span and situation model processing. The American Journal of Psychology, 117(2), 191-213. doi:10.2307/4149022

Radvansky, G. A., \& Copeland, D. E. (2006a). Memory retrieval and interference: Working memory issues. Journal of Memory and Language, 55(1), 33-46. doi:10.1016/j.jml.2006.02.001

Radvansky, G. A., \& Copeland, D. E. (2006b). Situation models and retrieval interference: Pictures and words. Memory, 14(5), 614 623. doi:10.1080/09658210600647714

Radvansky, G. A., Copeland, D. E., \& von Hippel, W. (2010). Stereotype activation, inhibition, and aging. Journal of Experimental Social Psychology, 46(1), 51-60. doi:10.1016/j.jesp.2009.09.010

Radvansky, G. A., Copeland, D. E., \& Zwaan, R. A. (2003). Brief report: Aging and functional spatial relations in comprehension and memory. Psychology and Aging, 18(1), 161-165. doi:10.1037/08827974.18.1.161

Radvansky, G. A., Gibson, B. S., \& McNerney, M. W. (2014). Working memory, situation models, and synesthesia. The American Journal of Psychology, 127(3), 325-342. doi:10.5406/amerjpsyc.127.3. 0325

Radvansky, G. A., Spieler, D. H., \& Zacks, R. T. (1993). Mental model organization. Journal of Experimental Psychology: Learning, Memory, and Cognition, 19(1), 95-114. doi:10.1037/0278-7393. 19.1.95

Radvansky, G. A., Wyer, R. S., Jr., Curiel, J. M., \& Lutz, M. F. (1997). Situation models and abstract ownership relations. Journal of Experimental Psychology: Learning, Memory, and Cognition, 23(5), 1233-1246. doi:10.1037/0278-7393.23.5.1233

Radvansky, G. A., \& Zacks, J. M. (2011). Event perception. Wiley Interdisciplinary Reviews: Cognitive Science, 2(6), 608-620. doi: $10.1002 /$ wcs. 133

Radvansky, G. A., \& Zacks, J. M. (2014). Event Cognition. London: Oxford University Press.

Radvansky, G. A., \& Zacks, R. T. (1991). Mental models and the fan effect. Journal of Experimental Psychology: Learning, Memory, and Cognition, 17(5), 940-953. doi:10.1037/0278-7393.17.5.940

Radvansky, G. A., Zacks, R. T., \& Hasher, L. (2005). Age and inhibition: The retrieval of situation models. The Journals of Gerontology Series B: Psychological Sciences and Social Sciences, 60(5), 276P278. doi:10.1093/geronb/60.5.P276

Radvansky, G. A., Zwaan, R. A., Curiel, J. M., \& Copeland, D. E. (2001). Situation models and aging. Psychology and Aging, 16(1), 145-160. doi:10.1037/0882-7974.16.1.145

Radvansky, G. A., Zwaan, R. A., Federico, T., \& Franklin, N. (1998). Retrieval from temporally organized situation models. Journal of Experimental Psychology: Learning, Memory, and Cognition, 24(5), 1224-1237. doi:10.1037/0278-7393.24.5.1224 
Reder, L. M., \& Anderson, J. R. (1980). A partial resolution of the paradox of interference: The role of integrating knowledge. Cognitive Psychology, 12(4), 447-472. doi:10.1016/0010-0285(80)90016-X

Reder, L. M., \& Wible, C. (1984). Strategy use in question-answering: Memory strength and task constraints on fan effects. Memory \& Cognition, 12(4), 411-419. doi:10.3758/BF03198302

Ribot, T. (1882). Diseases of Memory: An Essay in the Positive Psychology. Trench: Kegan Paul.

Roediger, H. L., \& Karpicke, J. D. (2006). Test-enhanced learning taking memory tests improves long-term retention. Psychological Science, 17(3), 249-255. doi:10.1111/j.1467-9280.2006.01693.x

Schmalhofer, F., \& Glavanov, D. (1986). Three components of understanding a programmer's manual: Verbatim, propositional, and situational representations. Journal of Memory and Language, 25(3), 279-294. doi:10.1016/0749-596X(86)90002-1

Seamon, J. G., Luo, C. R., Kopecky, J. J., Price, C. A., Rothschild, L., Fung, N. S., \& Schwartz, M. A. (2002). Are false memories more difficult to forget than accurate memories? The effect of retention interval on recall and recognition. Memory \& Cognition, 30(7), 1054-1064. doi:10.3758/BF03194323

Singer, M., \& Jakobson, L. S. (1991). Focussed memory search and stages of question answering. Canadian Journal of Psychology/ Revue Canadienne de Psychologie, 45(3), 367-380. doi:10.1037/ h0084298
Sohn, M. H., Anderson, J. R., Reder, L. M., \& Goode, A. (2004). Differential fan effect and attentional focus. Psychonomic Bulletin \& Review, 11(4), 729-734. doi:10.3758/BF03196627

Van Dijk, T. A., \& Kintsch, W. (1983). Strategies of Discourse Comprehension. New York: Academic Press.

Van Selst, M., \& Jolicoeur, P. (1994). A solution to the effect of sample size on outlier elimination. Quarterly Journal of Experimental Psychology, 47(3), 631-650. doi:10.1080/14640749408401131

Wickelgren, W. A. (1972). Trace resistance and the decay of long-term memory. Journal of Mathematical Psychology, 9(4), 418-455. doi: 10.1016/0022-2496(72)90015-6

Wixted, J., \& Cai, D. J. (2013). Memory Consolidation. The Oxford Handbook of Cognitive Neuroscience, Volume 1: Core Topics, 1, 436.

Wixted, J. T., \& Ebbesen, E. B. (1991). On the form of forgetting. Psychological Science, 2(6), 409-415. doi:10.1111/j.1467-9280. 1991.tb00175.x

Zwaan, R. A. (1994). Effect of genre expectations on text comprehension. Journal of Experimental Psychology: Learning, Memory, and Cognition, 20(4), 920-933. doi:10.1037/0278-7393.20.4.920

Zwaan, R. A., \& Radvansky, G. A. (1998). Situation models in language comprehension and memory. Psychological Bulletin, 123(2), 162185. doi:10.1037/0033-2909.123.2.162 